\title{
Опыт первичной интродукции некоторых видов Scutellaria Северного Тянь-Шаня в условиях предгорий Заилийского Алатау
}

\section{Experience of primary introduction of some Scutellaria species in terms of the Northern Tien Shan in the Trans-Ili Alatau foothills}

\author{
Съедина И. А., Отрадных И. Г. \\ Syedina I. A., Otradnykh I. G. \\ РГП на ПХВ «Институт ботаники и фитоинтродукции» Комитета лесного хозяйства и животного мира Министерства \\ экологии, геологии и природных ресурсов РК, г. Алматы, Казахстан.E-mail Phyto_bot15@mail.ru \\ RSE REU "Institute of Botany and Phytointroduction" Foresty and wildlife committee of Ministry of Ecology, Geology and Natural \\ Resources of the Republic of Kazakhstan, Almaty, Kazakhstan
}

\begin{abstract}
Pеферат. Приведены данные первичной интродукции Scutellaria titovii Juz., Scutellaria transiliensis Juz., Scutellaria przewalskii Juz., Scutellaria sieversii Bunge на коллекционном участке ботанического сада г. Алматы, расположенного в предгорной зоне Заилийского Алатау. Анализ декоративных свойств шлемника показал, что все изучаемые виды обладают высокими декоративными и адаптивными свойствами и пригодны для посадок в рокариях, альпинариях и как почвопокровное растение для укрепления щебнистых склонов.
\end{abstract}

Ключевые слова. Декоративность, интродукция, плодоношение, цветение, экологические условия.

Summary The primary introduction data of Scutellaria titovii Juz., S. transiliensis Juz., S. przewalskii Juz., S. sieversii Bunge at the collection of the Almaty Botanical Garden, located in Zailiysky Alatau foothill zone, is provided. The analysis of the decorative properties of Scutellaria showed that all studied species have high decorative and adaptive features and suitable for planting in rockeries, rock gardens and as a groundcover to strengthen gravelly slopes.

Key words. Decorativeness, environmental conditions, introduction, flowering, fruiting.

Интродукция является одним из основных направлений ботанических исследований как источник выявления, привлечения и всестороннего изучения новых ценных видов, форм и разновидностей растений из различных природных сообществ, представляющих интерес для использования в народном хозяйстве. Также испытываются хозяйственно-полезные дикорастущие виды растений, устойчивые к агрессивным условиям городской среды и усугублению аридности климата.

Одними из таких ценных растений являются виды рода Scutellaria Schrenk. - шлемник. Согласно данным сайта Ботанических садов Кью (Kew Science www.plantsoftheworldonline.org), род насчитывает более 460 видов, в Казахстане - 32, в Северном Тянь-Шане 8 видов (Юзепчук, 1954, Фисюн, 1964). Отличительной особенностью рода от других представителей семейства является отсутствие эфиромасличных железок (Цвелев, 1981). Растения рода Scutellaria Schrenk. (сем. Lamiaceae Lind1.) - многолетние или, изредка, однолетние травы, изредка полукустарники или кустарнички, со стеблями, одревесневающими при основании и травянистыми в верхней части. Листья черешковые, городчатые или зубчатые, реже цельнокрайние или немного рассеченные. Цветок - с колокольчатой чашечкой, двугубый (верхняя губа шлемовидная, нижняя плоская) с вогнутым гребешком. Цветки собраны в колосовидные или кистевидные соцветия на верхушках стеблей. Плоды - орешки сплюснуто-шаровидной или яйцевидной формы, бородавчатые, опушенные. Распространены в Восточной Сибири, на Дальнем Востоке, Средней Азии, Монголии, Китае, Японии, Северной Америке. Растет на сухих каменистых и глинистых горных склонах, реже в степи. Scutellaria galericulata L., S. baicalensis Georgi,, S. altaica Fischer ex Sweet широко используются в народной и официальной медицине многих стран. Их корни содержат эфирные масла, флавоноиды, крахмал, дубильные вещества, пирокатехины, смолы, сапонины 
кумарины, а также калий, кальция, магний и другие микроэлементы (Гольдберг и др., 1994). Большинство видов являются декоративными, образуя ажурные дерновины с густой листвой и длинными орнаментальными кистями красивых цветков, но в озеленении используется лишь малое их число. Наиболее известными в озеленении видами считаются Scutellaria altaica Fischer ex Sweet, S. orientalis L., S. grandiflora Sims, S. alpina L., S. tuvensis Juz. S. baicalensis Georgi, S. supina L. Шлемники используются для декорации берегов водоемов, для посадки по переднему краю бордюра, миксбордеров, каменистых горок и в качестве засухоустойчивого почвопокровного растения (Энциклопедия декоративных садовых растений. http://flower.onego.ru). Наибольшей популярностью в интродукции с целью получения лекарственного сырья пользуется Scutellaria baicalensis (Маняхин и др., 2013). В Казахстане ранее проводились интродукционные испытания трех видов щлемника: Scutellaria adsurgens M. Pop., S. supina L., S. turgaica Juz. (Растения природной флоры Казахстана ..., 1990).

Объектами наших исследований для первичной интродукции растений p. Scutellaria послужили следующие виды: Scutellaria titovii Juz., S. transiliensis Juz., S. przewalskii Juz., S. sieversii Bunge, привлеченные из природных популяций. Материал для интродукции (живые растения) был собран в весенне-летний период 2016-2018 гг. в ходе полевых маршрутно-рекогносцировочных обследований растительности гор Северного Тянь-Шаня в следующих регионах: Заилийский Алатау, Шу-Илейские горы, горы Сюгаты, Богуты, Кунгей Алатау, Киргизский Алатау. Интродукцию растений проводили по общепринятым методикам (Трулевич, 1991). Фенологические наблюдения проводятся по методике фенонаблюдений в ботанических садах (Бейдеман, 1974, Методика фенологических наблюдений ..., 1979). В ходе исследований за каждым видом ежегодно проводили регулярные наблюдения. При этом учитывали генеративное развитие растений (отрастание, цветение, плодоношение). Климатические условия ботанического сада г. Алматы, расположенного в предгорной зоне Заилийского Алатау, характеризуются небольшим количеством годовых осадков и резкими колебаниями суточных и годовых температур. Большая часть осадков выпадает в мае - июне (Утешев, 1952). Почвы - каштановые суглинки (Соколов и др., 1962).

Scutellaria titovii Juz. - шлемник Титова - эндемичный вид Шу-Илейских гор, полукустарничек 15-25 см высотой, стебли многочисленные, листья яйцевидные надрезанно-зубчатые 0,6-2,3 см длиной и 0,4-1,2 см шириной, сизые от волосистого опушения. Венчик до 2,5 см длиной, желтый с темно-пурпуровыми боковыми лопастями и кончиком верхней губы (рис. 1А). Литофит, обитает на щебнистых и каменистых местах. Вид входит в состав популяций таких редких видов, как Tulipa alberti Regel и Niedzwedzkia semiretschenskia B. Fedtsch., обитающих в Шу-Илейских горах (Кокорева и др., 2013).

Scutellaria transiliensis Juz. - шлемник заилийский, полукустарничек 12-40 см высотой, стебли многочисленные, восходящие, изогнутые, листья 0,7-3 см длиной, 0,3-2 см шириной. Венчик 2,5-3,5 см длиной, желтый с пурпуровым кончиком верхней губы и боковыми лопастями (рис. 1Б). Растет на каменистых склонах низкогорий. Встречается в Заилийском, Кунгей Алатау и Джунгарском Алатау. Входит в состав популяций редких видов Tulipa ostrovskiana Regel, Tulipa kolpakowskiana Regel и Anemone almaatensis Juz. (Кокорева и др., 2013).

Scutellaria sieversii Bunge - шлемник Сиверса, полукустарничек 7-15 см высотой, листья 0,52,5 см длиной, 1-1,5 см шириной. Венчик 1,8-2 см длиной, светло-желтый (рис. 1В). Растет на сухих каменистых, щебнистых и глинистых склонах низкогорий. Встречается в горах Сюгаты, Богуты, ШуИлейские горы. Вид входит в состав популяций редких видов Tulipa kolpakowskiana Regel, Ferula iliensis Korov. ex Fedtsch., Iris kolpakowskiana Regel, Iris kuschakewiczii B. Fedtsch., произрастающих в этом районе (Кокорева и др., 2013).

Scutellaria przewalskii Juz. - шлемник Пржевальского - полукустарничек 6-20 см высотой, стебли немногочисленные, восходящие. Листья 0,6-2,2 см длиной, 0,4-2 см шириной. Венчик 2-4 см длиной, желтый (рис. 1Г). Растет в злаково-полынных степях, на каменистых склонах. Встречается в Кунгей Алатау.

Для Scutellaria sieversii, S. titovii, S. transiliensis, учитывая их биологию произрастания в природных популяциях, были подготовлены участки с дренажем из смеси земли, щебня, песка и обломков камней в соотношении 2:1:1:1. Для выращивания Scutellaria przewalskii участок готовился с добавлением песка в соотношении 2:1. 

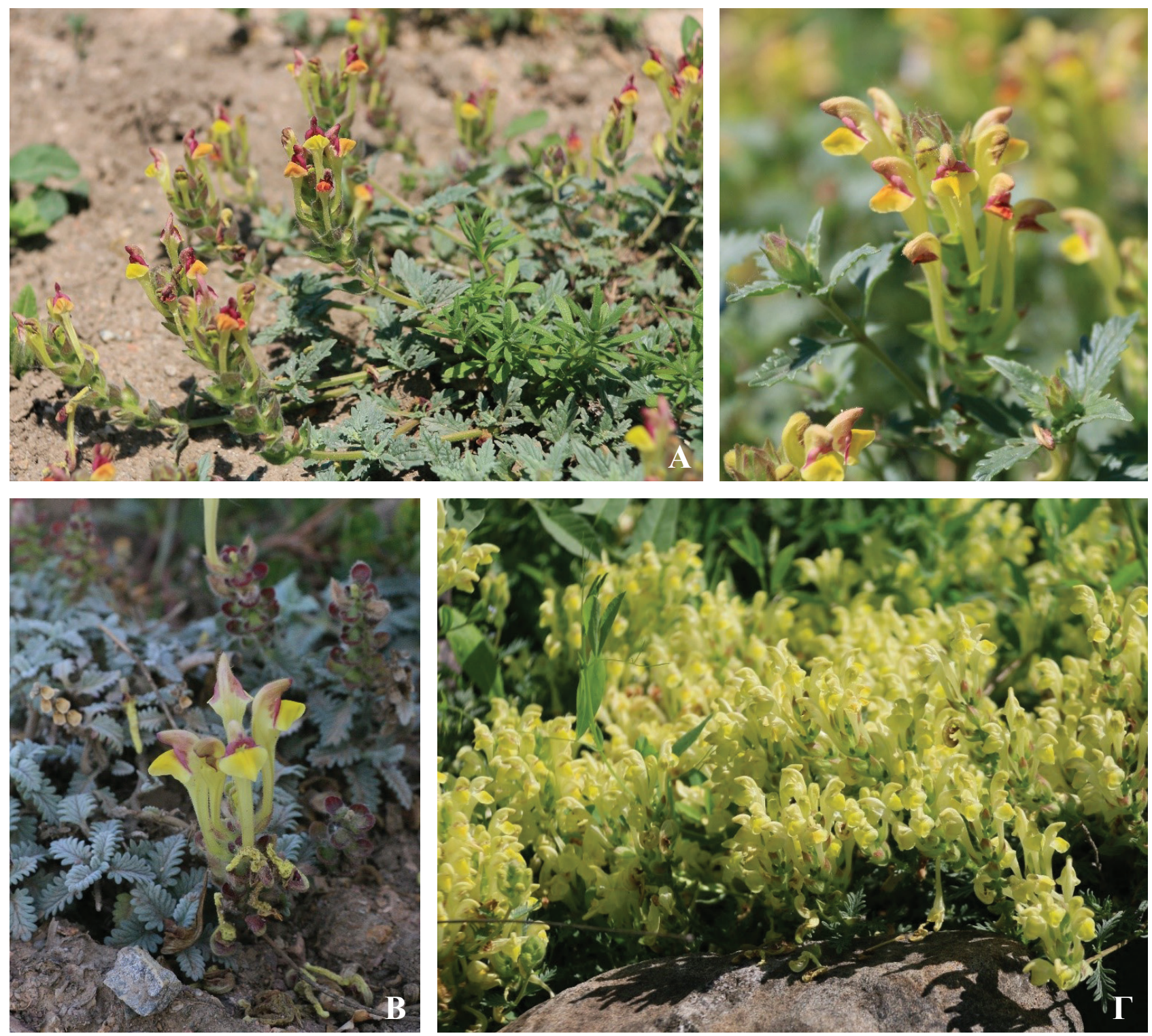

Рис. 1. Цветущее растение: А - Scutellaria titovii; Б - Scutellaria transiliensis; В - Scutellaria sieversii; Г-Scutellaria przewalskii (фото И. Отрадных).

Вегетация изучаемых видов шлемника начинается в конце марта - начале апреля, когда среднесуточная температура воздуха переходит отметку $+10^{\circ} \mathrm{C}$. В среднем, в конце апреля-начале мая растения вступают в период бутонизации, начало цветения отмечено в первой декаде мая. Во второй декаде мая наблюдается массовое цветение. Распускание цветков начинается с нижнего яруса колосовидного соцветия, которое постепенно вытягивается по мере зацветания расположенных выше. Период основного (первичного) цветения длится в течение 28-46 дней и зависит от погодных условий периода вегетации, одновременно идет созревание плодов. Рассыпавшиеся семена на участке дают самосев. Продолжительность цветения видов составила 93 (Scutellaria titovii) и 95 дней (S. sieversii), 103 (S. transiliensis), 108 дней (S. przewalskii). Такая длительность цветения достигнута за счет обрезки цветочных побегов и умеренного полива в засушливый период, что стимулировало продолжительное вторичное цветение с середины августа по октябрь. Перерыв в цветении составил 42-50 дней. Вторичное цветение заканчивается после первых заморозков (табл. 1). В природных местах произрастания плодоношение приходится на очень жаркий и засушливый период, когда температура воздуха превышает $30{ }^{\circ} \mathrm{C}$ (июль - начало августа). Вторичного цветения шлемников в природных популяциях мы не наблюдали. 
Средняя продолжительность фенологических фаз видов рода Scutellaria

\begin{tabular}{|c|c|c|c|c|c|c|c|c|}
\hline \multirow{3}{*}{ Вид } & \multirow{3}{*}{$\begin{array}{c}\text { Отраста- } \\
\text { ние }\end{array}$} & \multirow{3}{*}{$\begin{array}{c}\text { Бутони- } \\
\text { зация }\end{array}$} & \multicolumn{3}{|c|}{ Цветение } & \multirow{2}{*}{\multicolumn{2}{|c|}{ Плодоношение }} & \multirow{3}{*}{$\begin{array}{c}\text { Продолжи- } \\
\text { тельность } \\
\text { вегетации, } \\
\text { дней }\end{array}$} \\
\hline & & & \multirow{2}{*}{$\begin{array}{c}\text { первичное } \\
\frac{\text { Начало }}{\text { конец }}\end{array}$} & \multirow{2}{*}{$\begin{array}{c}\text { вторичное } \\
\frac{\text { Начало }}{\text { конец }}\end{array}$} & \multirow{2}{*}{$\begin{array}{l}\text { всего, } \\
\text { дней }\end{array}$} & & & \\
\hline & & & & & & Начало & конец & \\
\hline $\begin{array}{l}\text { Scutellaria } \\
\text { titovii }\end{array}$ & 5.04 & 28.04 & $\frac{12.05}{15.06}$ & $\underline{5.08}$ & 93 & 18.06 & 14.10 & 193 \\
\hline $\begin{array}{l}\text { Scutellaria } \\
\text { transiliensis }\end{array}$ & 28.03 & 21.04 & $\frac{12.05}{28.06}$ & $\frac{10.08}{12.10}$ & 108 & 27.06 & 19.10 & 205 \\
\hline $\begin{array}{l}\text { Scutellaria } \\
\text { przewalskii }\end{array}$ & 7.04 & 27.04 & $\frac{10.05}{25.06}$ & $\frac{14.08}{12.10}$ & 103 & 25.06 & 17.10 & 193 \\
\hline $\begin{array}{l}\text { Scutellaria } \\
\text { sieversii }\end{array}$ & 9.04 & 3.05 & $\frac{15.05}{13.06}$ & $\frac{3.08}{10.10}$ & 95 & 28.06 & 15.10 & 189 \\
\hline
\end{tabular}

Анализ декоративных качеств шлемника показал, что самые крупные соцветия 11,25 и 7,0 см длиной формируются у видов с приподнимающимися побегами - это Scutellaria transiliensis и Scutellaria przewalskii, с количеством цветков в одном соцветии 34,7 и 27,2 штук. Scutellaria titovii и Scutellaria sieversii относятся к стелющимся видам и имеют соцветия 4,5 и 5,9 см длиной с количеством цветков в соцветии 21,8 и 30,7 штук (табл. 2).

Таблица 2

Морфологические параметры генеративных органов видов Scutellaria

\begin{tabular}{|l|c|c|}
\hline \multicolumn{1}{|c|}{ Вид } & Средняя длина соцветия, см & $\begin{array}{c}\text { Среднее количество цветков в } \\
\text { соцветии, шт. }\end{array}$ \\
\hline Scutellaria titovii & 4,5 & 21,8 \\
\hline Scutellaria transiliensis & 11,3 & 34,7 \\
\hline Scutellaria przewalskii & 7,0 & 27,2 \\
\hline Scutellaria sieversii & 5,9 & 30,7 \\
\hline
\end{tabular}

Также нами был поставлен опыт по черенкованию полуодревесневших побегов Scutellaria transiliensis и S. przewalskii в открытый грунт в первой декаде мая (3.05). Для этого нами были сделаны траншеи, в которые насыпалась смесь из песка и земли 1:1 и брались полуодревесневшие черенки длиной 15 см. Температура воздуха в этот период составляла $+10 \ldots+25{ }^{\circ} \mathrm{C}$., черенкование проводилось без укрытия, но при регулярном увлажнении почвы в вечернее время. Приживаемость проходила в течении 20-25 дней. Отмечено, что приживаемость составила 85 \% Scutellaria transiliensis, 80 \% S. przewalskii. Спустя 43 дней после постановки опыта все высаженные экземпляры вступили в фазу цветения. Подзимний посев семян 2018 г. дал дружные всходы в середине апреля 2019 г., когда средняя температура воздуха превысила $+10^{\circ} \mathrm{C}$.

Ритм развития, продолжительность вегетационного периода в почвенно-климатических условиях предгорной зоны юго-востока Казахстана, высокая зимостойкость, незначительная степень поражения болезнями и вредителями показали высокую потенциальную приспособленность испытываемых видов шлемника в новых для него условиях. Особо можно отметить, что период цветения в культуре этих видов значительно увеличивается. В природе длительность цветения этих видов не превышает 30 дней (конец мая - июнь), в культуре при минимальном поливе продолжительность цветения составляет около 100 дней. Для увеличения продолжительности цветения нами проведена обрезка соцветий после отцветания. После перерыва (около 50 дней), совпадающего с наиболее сухим и жарким периодом, цветение возобновляется. Виды цветут до заморозков. В целом, неприхотливы и устойчивы в культуре, нетребовательны к плодородию, но необходим дополнительный дренаж, чтобы исключить вымокание и 
развитие грибковых болезней. Scutellaria засухо- и морозоустойчивые растения. Анализ декоративных свойств шлемника показал, что все изучаемые виды обладают высокими декоративными и адаптивными свойствами и пригодны для посадок в рокариях, альпинариях и как почвопокровное растение для укрепления щебнистых склонов.

\section{ЛИТЕРАТУРА}

Бейдеман И. Н. Методика изучения фенологии растений и растительных сообществ. - Новосибирск: Наука, 1974. $-138 \mathrm{c}$.

Гольдберг Е. Д., Дыгай А. М., Литвиненко В. И., Попов Т. П., Суслов Н. И. Шлемник байкальский: фитохимия и фармакологические свойства. Томск: Изд-во Том. ун-та, 1994. - 222 с.

Кокорева И. И., Отрадных И. Г., Съедина И. А., Лысенко В. В. Редкие растения Северного Тянь-Шаня. - Алматы. 2013. -208 c.

Маняхин А. Ю., Зорикова С. П., Зорикова О. Г. Интродукция шлемника байкальского в условиях юга Приморского края // Известия Самарского научного центра РАН, 2013. - Т. 15. - № 3(2). - С. 744-747.

Методика фенологических наблюдений в ботанических садах СССР // Бюл. Глав. ботан. сада, 1979. - Вып. 113. - C. 4-5.

Растения природной флоры Казахстана в интродукции. Справочник. - Алма-Ата: Гылым, 1990. - 285 с.

Соколов С. И., Ассинг И. А., Курмангалиев А. Б. Почвы Алма-Атинской области. - Алма-Ата: Изд-во АН КазССР, 1962. -424 c.

Tрулевич Н. В. Эколого-фитоценотические основы интродукции растений. - М.: Наука, 1991. - 216 с.

Утешев $\boldsymbol{A}$. C. Климаты Казахстана // Очерки по физической географии Казахстана. - Алма-Ата: Изд-во АН КазССР, 1952. - С. 155-197.

Фисюн В. В. Шлемник - Scutellaria L. // Флора КазССР: в 9 т. / под гл. ред. Н. В. Павлова. - Алма-Ата: Изд-во АН КазССР, 1964. - Т. 7. - С. 299-322.

Цвелев Н. Н. Порядок Губоцветные (Lamiales) // Жизнь растений. Цветковые растения. М.: Просвещение, 1981. - T. 5. - Ч. 2 - C. $400-413$.

Юзепчук C. B. Род 1244. Шлемник - Scutellaria L. // Флора CCCР: в 30 т. / начато при рук. и под гл. ред. В. Л. Комарова. - М. ; Л. : Изд-во АН СССР, 1954. - Т. 20. - С. 72-225.

Энииклопедия декоративных садовых растений. URL: http:// flower.onego.ru/other/scutella.html. (29.03.2020)

Plants of the Word Online Kew Science. URL: http://www.plantsoftheworldonline.org/Scutellaria (20.04.2020) 